\title{
Secondary fear of childbirth prolongs the time to subsequent delivery
}

Gunilla Sydsjö, Louise Angerbjorn, Sofie Palmquist, Marie Bladh, Adam Sydsjö and Ann Josefsson

\section{Linköping University Post Print}

\section{Tweet}

N.B.: When citing this work, cite the original article.

This is the pre-reviewed version of the following article:

Gunilla Sydsjö, Louise Angerbjorn, Sofie Palmquist, Marie Bladh, Adam Sydsjö and Ann Josefsson, Secondary fear of childbirth prolongs the time to subsequent delivery, 2013, Acta Obstetricia et Gynecologica Scandinavica, (92), 2, 210-214.

which has been published in final form at:

http://dx.doi.org/10.1111/aogs.12034

Copyright: Informa Healthcare / Wiley-Blackwell http://eu.wiley.com/WileyCDA/Brand/id-35.html

Postprint available at: Linköping University Electronic Press http://urn.kb.se/resolve?urn=urn:nbn:se:liu:diva-96494 


\section{Secondary fear of childbirth prolongs the time to subsequent delivery}

Gunilla Sydsjö PhD, Louise Angerbjörn Med stud, Sofie Palmquist Med stud, Marie Bladh MA, Adam Sydsjö PhD, MD, Ann Josefsson PhD, MD.

Division of Obstetrics and Gynecology, Department of Clinical and Experimental Medicine, Faculty of Health Sciences, Linköping University, Department of Obstetrics and Gynecology in Linköping, County Council of Östergötland, Linköping, Sweden

\section{Correspondence:}

Gunilla Sydsjö, Division of Obstetrics and Gynecology, Department of Clinical and

Experimental Medicine, Faculty of Health Sciences, Linköping University, SE-581 85

Linköping, Sweden

Email: Gunilla.Sydsjo@lio.se 


\begin{abstract}
Objective: Most pregnant women are anxious about the delivery and up to $30 \%$ develop varying degrees of fear of childbirth (FOC). Secondary FOC occurs in parous women who have experienced a traumatic delivery. The aim of this study was to investigate the time to subsequent delivery and delivery outcome in women with secondary FOC, compared to a reference group.
\end{abstract}

Setting: South-east Sweden

Sample: 356 parous pregnant women with secondary FOC and a reference group of 634 parous women without FOC.

Design: Descriptive, retrospective case-control study.

Main outcome measures: Time to next pregnancy and delivery outcome.

Results: More women with secondary FOC had a longer interval to subsequent delivery compared to parous women without FOC $(\mathrm{p}=0.005)$. Women with secondary FOC had 5.2 times higher probability of having a cesarean section than the reference group. Women with secondary FOC also had on average 40 minutes longer duration of active labor than women without FOC $(\mathrm{p}<0.001)$.

Conclusions: Secondary fear of childbirth prolongs the time to subsequent delivery, the active phase of labor itself and it increases the risk for cesarean section. 
Secondary fear of childbirth

\section{Keywords}

Fear of childbirth, Pregnancy, fear of childbirth , Delivery, Cesarean section

\section{Abbreviations}

FOC, fear of childbirth; CS, cesarean section, ANC, antenatal clinic, BMI, body mass index.

\section{Key Message}

Women with secondary fear of childbirth after a previous traumatic delivery experience had a longer time interval to subsequent delivery and were more often delivered with CS. 


\section{Introduction}

During pregnancy many women experience both anticipation and anxiety about the upcoming delivery, a normal feeling and process that may help the women to prepare themselves (1). Some women develop fear of childbirth (FOC) which may be a mild, moderate, severe or phobic fear (tocophobia) (2). The more severe forms of FOC cause psychological suffering and have a negative influence on the women's everyday life. Studies show that the prevalence of FOC in pregnant women is $18-31 \%(3,4)$, and the prevalence of severe FOC is $2-11 \%(5-$ 7). Women can describe different types of fear. Some examples are fear of intolerable pain, injury or death of the infant or the woman herself, being incapable of giving birth, tearing apart, and losing control of the situation during labor or the possible need of an instrumental delivery. Lack of trust in the obstetric personnel is also commonly expressed (1,8-10). Secondary FOC occurs in parous women who experienced their prior delivery as a traumatic event, sometimes despite a normal delivery seen from a medical point of view $(1,2,6,9,11,12)$. Severe FOC has great negative impact on the affected woman. It may cause her to avoid pregnancy or choose a legal abortion although she longs for a child, because the thought of giving birth is overwhelming $(2,5)$. It also seems to prolong the time to and causes fewer subsequent deliveries $(9,13)$. FOC has also been shown to affect the delivery process, the expected child and the puerperium (14-17). Women with severe forms have a higher frequency of instrumental deliveries, emergency cesarean section (CS) and have a longer duration of labor $(7,15-19)$.

In a previous study we found that after extended support as many as $50 \%$ of the women with severe FOC who in early pregnancy wanted an elective CS finally had a vaginal delivery (20). Previous research has mainly focused on reasons for, characteristics of and possible treatment of FOC in general. Only a few studies have dealt with to what extent secondary FOC affects future reproduction. Therefore the primary aim of this study was to investigate differences in 
time to subsequent delivery and secondary to compare delivery outcome for women with a previous subjective traumatic delivery experience, i.e. a secondary FOC, compared to a reference group. 


\section{Material and Methods}

This is a retrospective case-control study with prospectively collected data. The population from which the study sample was selected consisted of all pregnant parous women who attended the antenatal clinics (ANC) and gave birth in two cities (Värnamo and Linköping) in the southeast region of Sweden during the years 2001-2007. In total approximately 23000 women.

Of all women referred from the ANC clinics to the special unit of psychosocial obstetrics at the Departments of Obstetrics and Gynecology for further treatment due to fear because of a prior subjective traumatic delivery experience, 608 women were diagnosed as having severe FOC according to DSM-IV criteria i.e. the American Psychiatric Associations diagnostic criteria for severe phobia. The diagnostic interviews were done either by a psychotherapist or an obstetrician at the special unit. Women who gave birth at other hospitals, moved out of the area or had a late spontaneous abortion were excluded. Finally, 356 women remained in the index group.

As a reference group we chose 634 women who gave birth on the same day as the index women at the two delivery wards. The only exclusion criteria were being a primipara and referral to the special unit of psychosocial obstetrics for FOC during this pregnancy. Pregnancy and delivery data was obtained from the women's medical records. The variables extracted were age, body mass index (BMI), civil status, occupation, smoking, spontaneous abortion, legal abortion, parity (present pregnancy included), previous CS, previous obstetric complications (defined as any obstetric diagnosis other than normal delivery), time to subsequent delivery in years, mode of delivery, duration of active labor (defined as time from cervix dilated $4 \mathrm{~cm}$ to delivery).

Statistics 
All statistical analyzes were performed using IBM SPSS Version 19 (Armonk, NY, USA). Statistical analyzes included Pearson's chi-squared test in order to estimate bivariate differences. ANOVA was used when a variable contained more than two levels. MannWhitney's U-test was used to compare median values on time to subsequent delivery and active labor since these variables were not normally distributed. Kaplan-Meier survival analysis was performed in order to investigate time between pregnancies between the two groups. In addition, logistic regression was performed with previous obstetric complications as dependent variables. Moreover, Cox regressions were performed with time between pregnancies and active labor as outcomes. For the latter analysis data was censored for emergency cesarean sections. The independent variables were FOC, age, BMI, civil status, occupation, smoking, parity, type of abortion and time to subsequent delivery. In all analyzes, a p-value of $\leq 0.05$ was considered significant. For the statistical analyzes, the variables smoking, previous CS and previous obstetric complications were categorized as yes and no. Duration of active labor was measured in minutes for calculation of median values and all elective CS were excluded.

The study was approved by the Regional Ethical Review Board in Linköping. 


\section{Results}

As shown in Table 1 and Table 2, there were differences between the two groups concerning age at present delivery, parity, previous CS and previous obstetric complications. No significant differences were found concerning BMI, civil status, occupation, smoking, spontaneous abortion or legal abortion. A logistic regression showed that women with secondary FOC had a 3.7 times higher probability of having had a previous obstetric complication, compared to women without FOC (Table 2).

The analysis of time to subsequent delivery in years shows that there was a borderline difference in time to subsequent delivery between the two groups ( $\mathrm{p}=0.049)$. A larger proportion of the women in the index group than in the reference group waited six years or more to subsequent delivery. The median waiting time in the two groups did not differ (median waiting time was 3 years in both groups). Figure 1, displays the cumulative survival time within the two groups limiting the analysis to those who had waited 10 years or less. A significant difference between the two groups was detected $\left(\log \operatorname{rank} \operatorname{chi}^{2}=5.91, \mathrm{p}=0.015\right)$. This was also verified in a Cox regression on time between pregnancies (measured in years), revealing that women with FOC have a higher hazard ratio of waiting time compared to women without FOC when adjusting for socio-demographic variables (Table 2). As shown in Table 3, there was a difference in mode of delivery between the two groups. Elective and emergency CS occurred more frequently in the index group. There was also a difference between the two groups concerning duration of active labor (all elective CS excluded), defined as time from cervix dilated $4 \mathrm{~cm}$ to delivery. Women in the index group had a longer duration than women in the reference group. Women with secondary FOC had a 5.2 times higher probability of having a CS than the reference group. Women with secondary FOC had a higher hazard ratio for prolonged duration of active labor than women with FOC ( $p=0.002)$, when adjusting for socio-demographic variables.. 


\section{Discussion}

We found that women with secondary FOC after a previous traumatic delivery experience had a longer time interval to subsequent delivery and were more often delivered with CS. Women with a secondary FOC also had a longer duration of the active phase of labor than women without FOC.

The fact that women with secondary FOC had a longer interval to subsequent delivery has been studied during the 1990s with similar findings $(9,13)$. The present study showed a difference in mode of delivery between the two groups, since CS was 5.2 times more frequent in the index group. When considering our results it is important to note that $30.6 \%$ of the index group had had a previous CS, compared to $12.9 \%$ in the reference group. This may have affected the rate of CS since a previous CS may constitute a higher risk for repeated surgical delivery (7). Also, the counseling for the woman with a secondary FOC might have led to a decision for a planned CS. The reason might in those cases be both medical and psychological.

We also found that women with secondary FOC had on average a longer duration of active labor than women without FOC, when excluding all elective CS and holding all other factors constant. A suggested mechanism behind prolonged labor in women with FOC is the elevated levels of plasma adrenalin, which might inhibit uterine contractions $(18,21)$. This is supported by a study from 1999, which showed that the first stage of labor was on average 101 minutes longer and the second stage on average 15 minutes longer in women with FOC (9). Also, in a recent study by Adams et al. it was found that women with symptoms of FOC measured with a psychometric instrument, W-DEQ, during pregnancy, had a longer duration of labor (22). This study included only parous women and is therefore comparable with the present one. Other studies have shown results that point in the opposite direction. A study from 1997 showed that women with FOC had shorter duration of labor than a reference group, regardless 
of parity (20). The authors pointed out a possible link to a greater proportion of the index women having had an induced labor, which could have resulted in a more active management of labor and more psychological support. Besides, the index group was smaller than the present one, with only 57 women compared to 356 in our study. A study from 1998, including both primiparous and parous women, could not show that FOC prolonged the duration of labor (17). Here the index group consisted of 88 women.

A strength of this study was a relatively large, sample with a reference group approximately twice the size of the index group. Also, the reference group was similar to the index group concerning background factors. In addition, the material consisted of women from two cities of different sizes, one urban and one rural with different kinds of hospitals, which further strengthens the study. Since a difference in the prevalence of FOC has been shown between urban and rural areas (10), this should make the material more representative for a general parous pregnant population.

A potential limitation of this study was the possibility that a few women in the reference group might have had a traumatic delivery experience and an undiagnosed FOC, and did not communicate that to their midwife or other caretakers. The women with a secondary FOC in this study all received individual counseling and treatment for their FOC. Without this intervention the differences presented in this study might have been greater. Another substantial limitation was the lack of a uniform definition of FOC. Today, different diagnoses are used and therefore FOC is often masked by other diagnoses. A more distinct definition could help to distinguish FOC from other obstetric diagnoses and provide more knowledge about the condition.

In conclusion, secondary FOC was found to prolong the time to subsequent delivery, the active phase of labor itself and increase the risk for cesarean section. We conclude that maximal effort is necessary to avoid traumatic delivery experiences during the first delivery. 


\section{Funding}

This study was supported by grants from The Health Research Council of the Southeast of Sweden and ALF, County Council of Östergötland.

\section{Conflicts of Interest}

The authors have stated explicitly that there are no conflicts of interest in connection with this article. 


\section{References}

1. Sjogren B. Reasons for anxiety about childbirth in 100 pregnant women. J Psychosom Obstet Gynaecol 1997; 18: 266-72.

2. Hofberg K, Brockington I. Tokophobia: an unreasoning dread of childbirth. A series of 26 cases. Br J Psychiatry 2000; 176: 83-5.

3. Nilsson C, Lundgren I, Karlstrom A, Hildingsson I. Self reported fear of childbirth and its association with women's birth experience and mode of delivery: A longitudinal population-based study. Women Birth 2011; epub.

4. Haines H, Pallant JF, Karlstrom A, Hildingsson I. Cross-cultural comparison of levels of childbirth-related fear in an Australian and Swedish sample. Midwifery 2011; 27: 560-7.

5. Zar M, Wijma K, Wijma B. Relations between anxiety disorders and fear of childbirth during late pregnancy. Clin Psychol Psychother 2002; 9: 122-130.

6. Nieminen K, Stephansson O, Ryding EL. Women's fear of childbirth and preference for Formaterat: Svenska (Sverige) cesarean section--a cross-sectional study at various stages of pregnancy in Sweden. Acta Obstet Gynecol Scand 2009; 88: 807-13.

7. Sydsjo G, Sydsjo A, Gunnervik C, Bladh M, Josefsson A. Obstetric outcome for women who received individualized treatment for fear of childbirth during pregnancy. Acta Obstet Gynecol Scand 212;91:44-9.

8. Geissbuehler V, Eberhard J. Fear of childbirth during pregnancy: a study of more than 8000 pregnant women. J Psychosom Obstet Gynaecol 2002; 23: 229-35. 
9. Saisto T, Ylikorkala O, Halmesmaki E. Factors associated with fear of delivery in second pregnancies. Obstet Gynecol 1999; 94: 679-82.

10. Melender HL. Experiences of fears associated with pregnancy and childbirth: a study of 329 pregnant women. Birth 2002; 29: 101-11.

11. Rouhe H, Salmela-Aro K, Halmesmaki E, Saisto T. Fear of childbirth according to parity, gestational age, and obstetric history. BJOG 2009; 116: 67-73.

12. Beck CT. Birth trauma: in the eye of the beholder. Nurs Res 2004; 53: 28-35.

13. Gottvall K, Waldenstrom U. Does a traumatic birth experience have an impact on future reproduction? BJOG 2002; 109: 254-60.

14. Crandon AJ. Maternal anxiety and neonatal wellbeing. J Psychosom Res 1979; 23: 1135.

15. Crandon AJ. Maternal anxiety and obstetric complications. J Psychosom Res 1979; 23: $109-11$.

16. Laursen M, Johansen C, Hedegaard M. Fear of childbirth and risk for birth complications in nulliparous women in the Danish National Birth Cohort. BJOG 2009; 116: $1350-5$.

17. Ryding EL, Wijma B, Wijma K, Rydhstrom H. Fear of childbirth during pregnancy may increase the risk of emergency cesarean section. Acta Obstet Gynecol Scand 1998; 77: $542-7$. 
18. Lederman RP, Lederman E, Work BA,Jr, McCann DS. The relationship of maternal anxiety, plasma catecholamines, and plasma cortisol to progress in labor. Am J Obstet Gynecol 1978; 132: 495-500.

19. Waldenstrom U, Hildingsson I, Ryding EL. Antenatal fear of childbirth and its association with subsequent caesarean section and experience of childbirth. BJOG 2006; 113: $638-46$.

20. Sjogren B, Thomassen P. Obstetric outcome in 100 women with severe anxiety over childbirth. Acta Obstet Gynecol Scand 1997; 76: 948-52.

21. Lederman RP, Lederman E, Work B,Jr, McCann DS. Anxiety and epinephrine in multiparous women in labor: relationship to duration of labor and fetal heart rate pattern. Am J Obstet Gynecol 1985; 153: 870-7.

22. Adams S, Eberehard-Gran M, Eskild A. Fear of childbirth and duration of labour: a study of 2206 women with intended vaginal delivery. BJOG 2012; 119:1238-46. 
Table 1. Socio-demographic variables of the studied women.

\begin{tabular}{|c|c|c|c|c|c|}
\hline & $\begin{array}{l}\text { Index } \\
\mathrm{n}=356 \\
\end{array}$ & $\begin{array}{c}\text { roup } \\
\%\end{array}$ & $\begin{array}{l}\text { Refere } \\
n=634\end{array}$ & $\begin{array}{l}\text { nce group } \\
\% \\
\end{array}$ & \\
\hline $\begin{array}{l}\text { Age* } \\
\leq 24 \text { years } \\
25-34 \text { years } \\
\geq 35 \text { years }\end{array}$ & $\begin{array}{l}15 \\
250 \\
88\end{array}$ & $\begin{array}{l}4.2 \\
70.3 \\
24.9\end{array}$ & $\begin{array}{l}37 \\
380 \\
211\end{array}$ & $\begin{array}{l}5.9 \\
60.5 \\
33.6\end{array}$ & 0.084 \\
\hline $\begin{array}{l}\text { BMI* } \\
\leq 18.9 \\
19.0-24.9 \\
25.0-29.9 \\
\geq 30.0\end{array}$ & $\begin{array}{l}5 \\
190 \\
98 \\
49\end{array}$ & $\begin{array}{l}1.5 \\
55.6 \\
28.7 \\
14.3\end{array}$ & $\begin{array}{l}16 \\
349 \\
174 \\
81\end{array}$ & $\begin{array}{l}2.6 \\
56.3 \\
28.1 \\
13.1\end{array}$ & 0.403 \\
\hline $\begin{array}{l}\text { Civil status } \\
\text { Married/Cohabiting } \\
\text { Single }\end{array}$ & $\begin{array}{l}345 \\
9\end{array}$ & $\begin{array}{l}97.5 \\
2.5\end{array}$ & $\begin{array}{l}612 \\
18\end{array}$ & $\begin{array}{l}97.1 \\
2.9\end{array}$ & 0.772 \\
\hline $\begin{array}{l}\text { Occupation } \\
\text { Occupied } \\
\text { Non-occupied }\end{array}$ & $\begin{array}{l}315 \\
18\end{array}$ & $\begin{array}{l}94.6 \\
5.4\end{array}$ & $\begin{array}{l}542 \\
31\end{array}$ & $\begin{array}{l}94.6 \\
5.4\end{array}$ & 0.998 \\
\hline $\begin{array}{l}\text { Smoking } \\
\text { Yes } \\
\text { No }\end{array}$ & $\begin{array}{l}60 \\
294\end{array}$ & $\begin{array}{l}16.9 \\
83.1\end{array}$ & $\begin{array}{l}83 \\
547\end{array}$ & $\begin{array}{l}13.2 \\
86.8\end{array}$ & 0.107 \\
\hline $\begin{array}{l}\text { Parity (present pregnancy } \\
\text { included) } \\
2 \text { children } \\
\geq 3 \text { children }\end{array}$ & $\begin{array}{l}295 \\
61\end{array}$ & $\begin{array}{l}82.9 \\
17.1\end{array}$ & $\begin{array}{l}410 \\
224\end{array}$ & $\begin{array}{l}64.7 \\
35.3\end{array}$ & $<0.001$ \\
\hline $\begin{array}{l}\text { Spontaneous abortion } \\
\text { Yes } \\
\text { No }\end{array}$ & $\begin{array}{l}90 \\
265\end{array}$ & $\begin{array}{l}25.4 \\
74.6\end{array}$ & $\begin{array}{l}181 \\
450\end{array}$ & $\begin{array}{l}28.7 \\
71.3\end{array}$ & 0.261 \\
\hline $\begin{array}{l}\text { Legal abortion } \\
\text { Yes } \\
\text { No }\end{array}$ & $\begin{array}{l}67 \\
288\end{array}$ & $\begin{array}{l}18.9 \\
81.1\end{array}$ & $\begin{array}{l}116 \\
514\end{array}$ & $\begin{array}{l}18.4 \\
81.6\end{array}$ & 0.858 \\
\hline $\begin{array}{l}\text { Previous CS } \\
\text { Yes } \\
\text { No }\end{array}$ & $\begin{array}{l}109 \\
247\end{array}$ & $\begin{array}{l}30.6 \\
69.4\end{array}$ & $\begin{array}{l}82 \\
552\end{array}$ & $\begin{array}{l}12.9 \\
87.1\end{array}$ & $<0.001$ \\
\hline $\begin{array}{l}\text { Previous obstetric } \\
\text { complications noted in the } \\
\text { woman's record } \\
\text { Yes } \\
\text { No }\end{array}$ & $\begin{array}{l}86 \\
270\end{array}$ & $\begin{array}{l}24.2 \\
75.8\end{array}$ & $\begin{array}{l}53 \\
581\end{array}$ & $\begin{array}{l}8.4 \\
91.6\end{array}$ & $<0.001$ \\
\hline
\end{tabular}


Table 2. Unadjusted and adjusted logistic regression and linear regression on obstetric outcomes for women with and without severe FOC.

\begin{tabular}{|c|c|c|c|c|c|c|c|c|}
\hline \multirow[b]{2}{*}{$\begin{array}{l}\text { Depen } \\
\text { dent }\end{array}$} & \multirow[b]{2}{*}{ Independent } & & \multicolumn{3}{|c|}{ Unadjusted } & \multicolumn{3}{|c|}{ Adjusted** } \\
\hline & & & $\mathrm{OR} / ß$ & $95 \% \mathrm{CI}$ & p-value & OR & $95 \%$ CI & p-value \\
\hline \multicolumn{9}{|c|}{ Previous obstetric complication* } \\
\hline & Group & Reference & & Reference & & & Reference & \\
\hline & & Index & 2.55 & 1.64-3.97 & $<0.001$ & 3.17 & $1.92-5.23$ & $<0.001$ \\
\hline \multicolumn{9}{|c|}{ Active labor $\$$} \\
\hline & & Reference & & Reference & & & Reference & \\
\hline & Group & Index & 1.36 & $1.15-1.61$ & $<0.001$ & 1.33 & $1.11-1.59$ & 0.002 \\
\hline \multicolumn{9}{|c|}{ Time between pregnancies $\$$} \\
\hline & Group & Reference & & Reference & & & Reference & \\
\hline & & Index & 1.09 & $0.96-1.25$ & 0.184 & 1.22 & $1.06-1.40$ & 0.005 \\
\hline
\end{tabular}

*logistic regression

**Adjusted for group, age when giving birth, civil status, smoking, BMI, No. of children, miscarriage and induced abortion. The analysis of active labor has, in addition to previously mentioned variables, also been adjusted for time between pregnancies.

${ }^{\$}$ Cox regression, where censoring for cesarean sections has been applied in the analysis of a active labor. 
Table 3. Delivery outcome in present pregnancy.

\begin{tabular}{|c|c|c|c|c|c|}
\hline & \multicolumn{2}{|c|}{ Index group } & \multicolumn{2}{|c|}{ Reference group } & \multirow[t]{2}{*}{$\mathbf{P}$} \\
\hline & $n=356$ & $\%$ & $n=634$ & $\%$ & \\
\hline \multicolumn{6}{|l|}{ Mode of delivery } \\
\hline $\begin{array}{l}\text { Non-instrumental vaginal } \\
\text { delivery }\end{array}$ & 209 & 58.9 & 545 & 86.1 & $<0.001$ \\
\hline Vacuum extraction (VE) & 11 & 3.1 & 24 & 3.8 & \\
\hline Emergency CS & 43 & 12.1 & 32 & 5.1 & \\
\hline Elective CS & 92 & 25.9 & 32 & 5.1 & \\
\hline $\begin{array}{l}\text { Duration of active labor } \\
\text { (minutes) }\end{array}$ & \multirow{2}{*}{\multicolumn{2}{|c|}{$179 / 2-749$}} & & & \\
\hline Median/range* minutes & & & \multicolumn{2}{|c|}{$122 / 1-619$} & $<0.001^{*}$ \\
\hline
\end{tabular}

*Mann-Whitney U-test has been used to compare median value. All elective CS excluded. 
Figure 1. Cumulative survival probability within index and control groups, limited to women with a waiting time of 10 years or less.

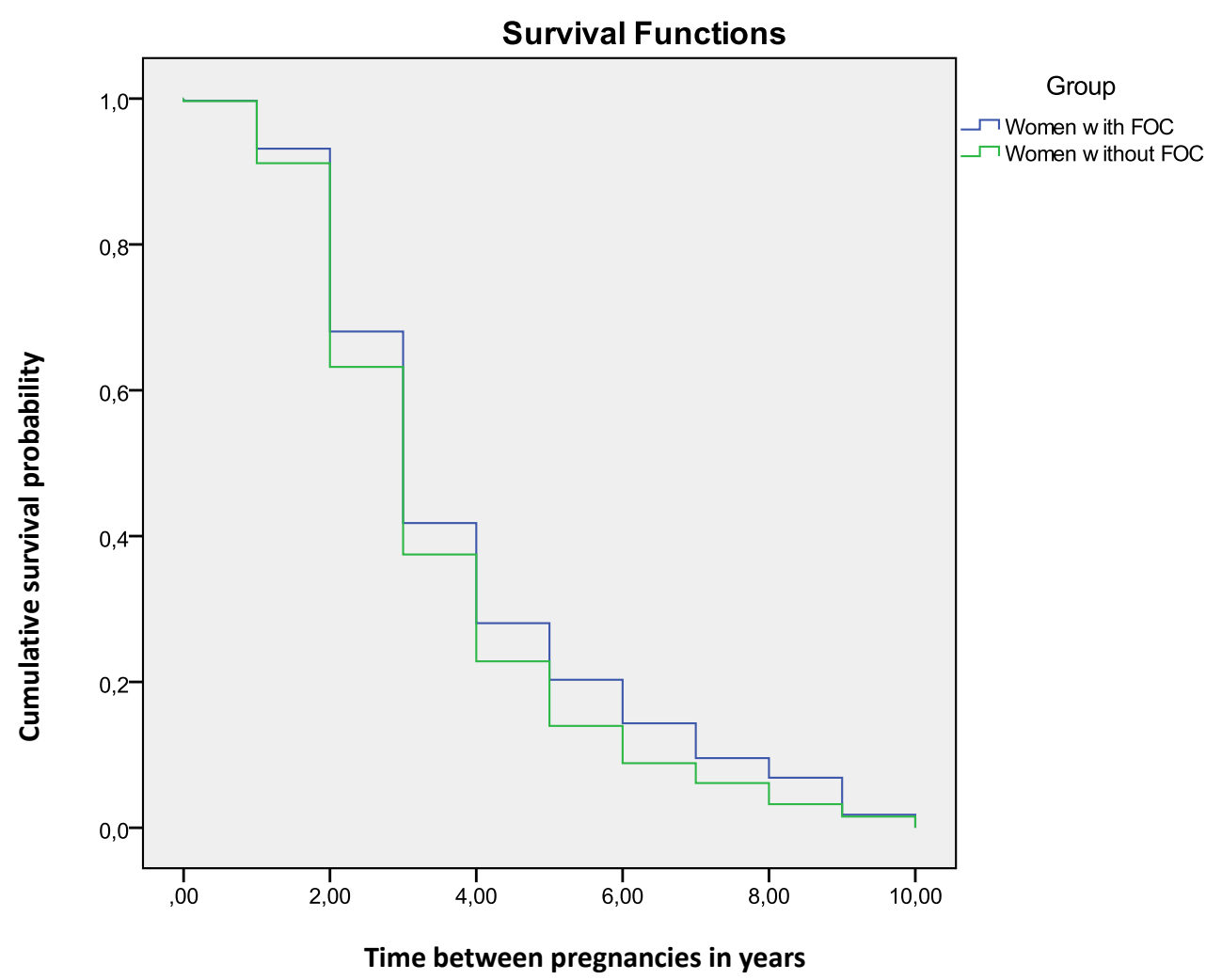

